\title{
aparcamiento en Breuninger
}

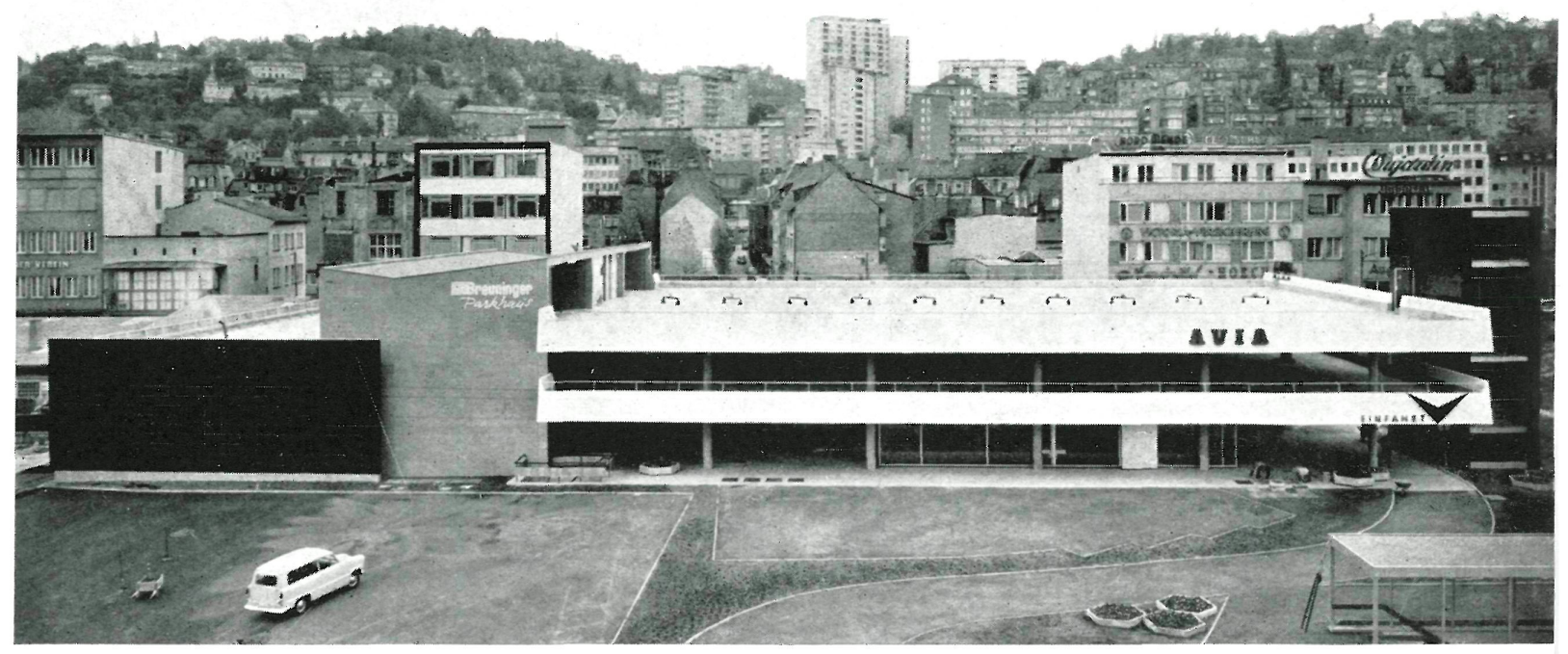

$138-24$

El problema del estacionamiento de vehículos en las grandes ciudades, precisamente en sus centros vitales, de comercio y de relación, se agudiza con el incremento incesante de automóviles. Los Municipios demuestran su preocupación creando lugares y espacios capaces para albergarlos. Esto mismo hacen, con un deseo muy encomiable, las grandes casas comerciales, de la que es buena muestra la Breuninger, de Stuttgart, uno de los más poderosos comercios de tejidos de la capital.

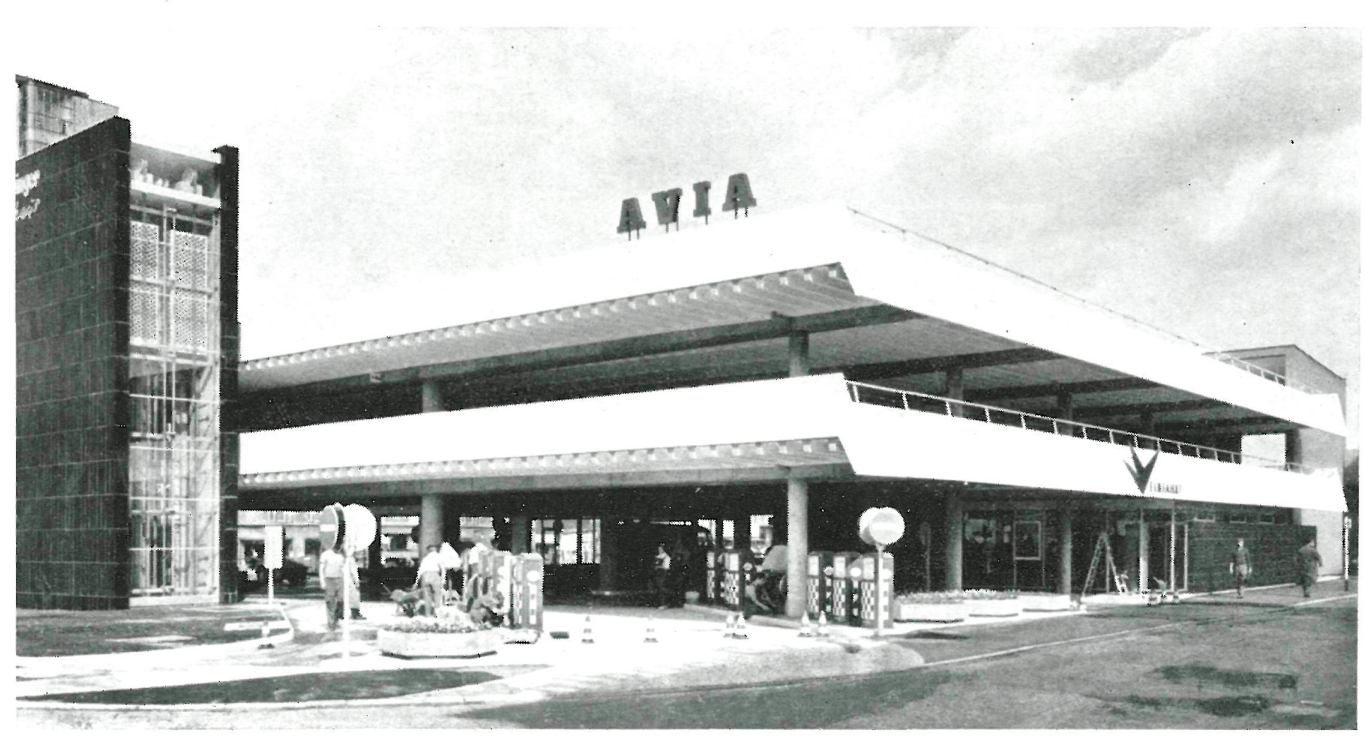

GERD WIEGAND, arquitecto

H. HANUSCH, ingeniero

BAUBURO BREUNINGER, R. CZERMAK

arquitecto

$W$ FOERSTER, ingeniero

KARL CRONAUER, Ingeniero 


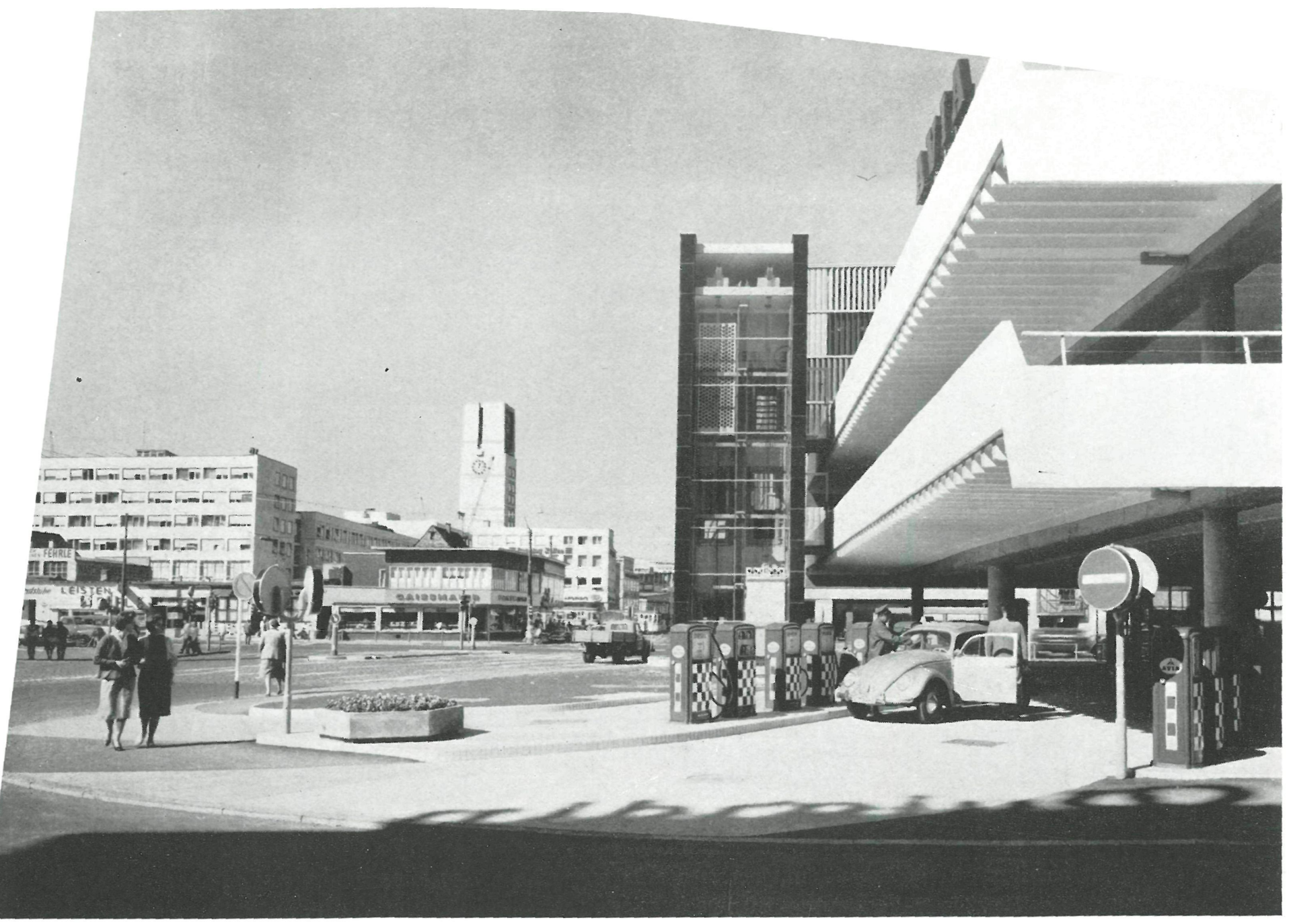

montacargas

Debido al reducido solar disponible, en las inmediaciones de la casa central, hubo que recurrir a una solución en altura, si bien con limitaciones determinadas municipales en este aspecto. Por todo ello, se disponen las plantas necesarias en dos sobre el nivel de la calle y otras dos enterradas. Así se alcanza la capacidad prevista de 311 coches, en 2/3 de ese número en los sótanos.

Los soportes se han colocado de tal forma que permitan la máxima diafanidad y una disposición de vehículos en batería sencilla o doble--según los casos-con ángulo de 45, previendo la posibilidad de ampliar su capacidad, recurriendo a colocación según ángulo de $90^{\circ}$.

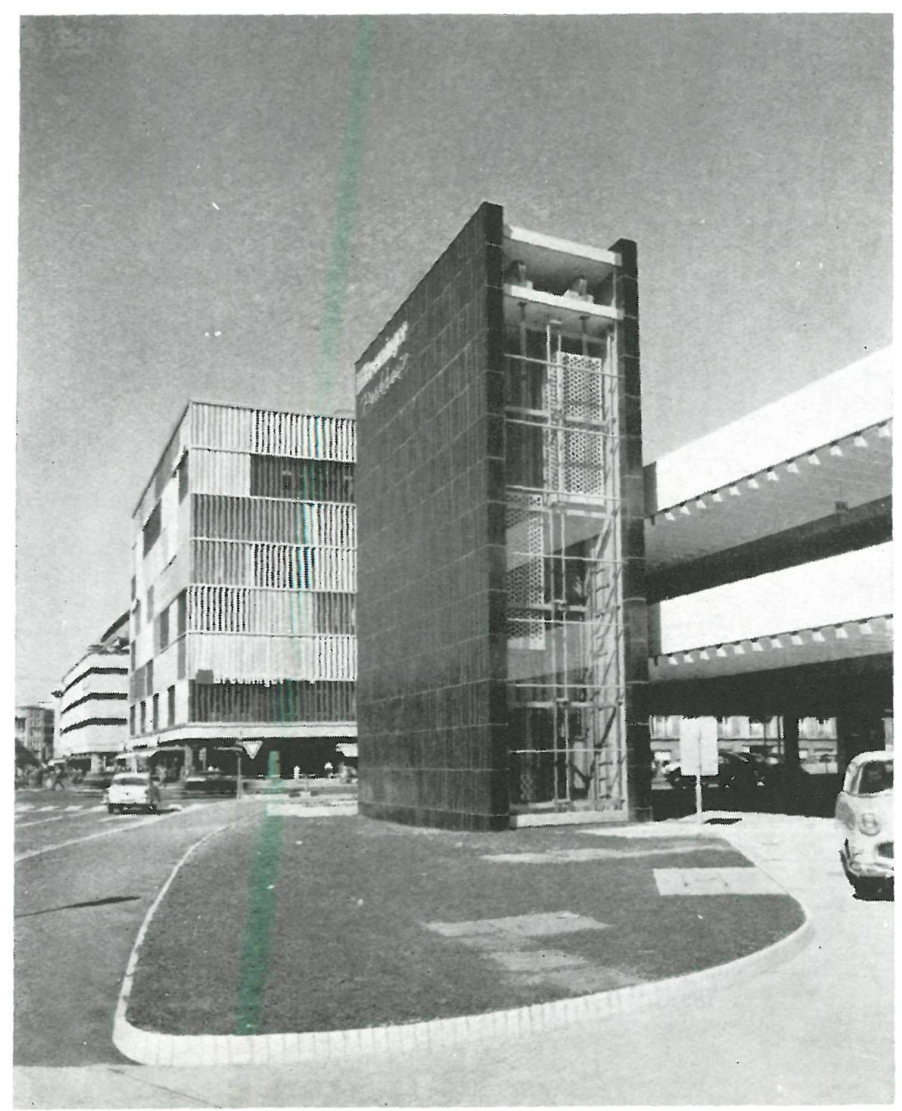




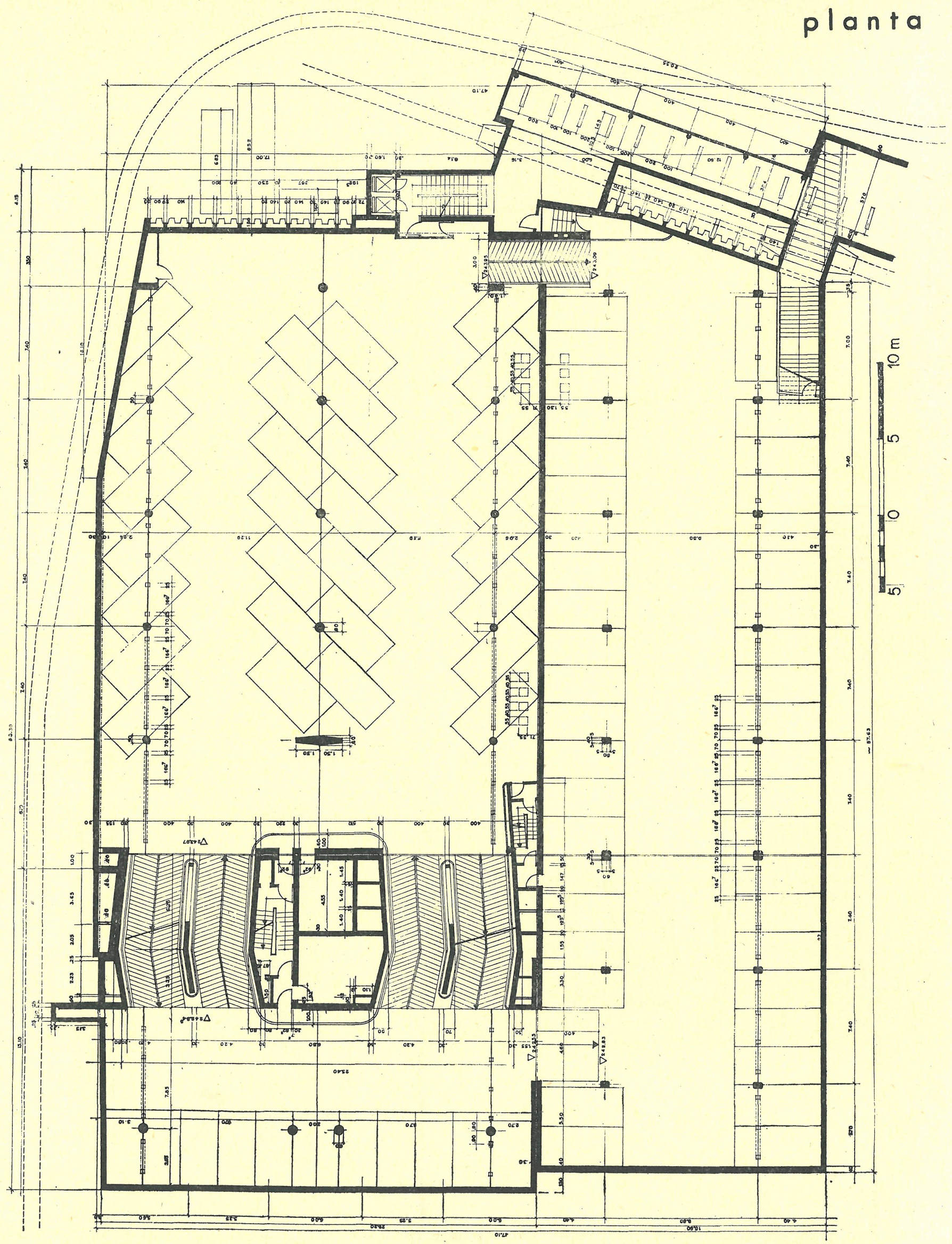




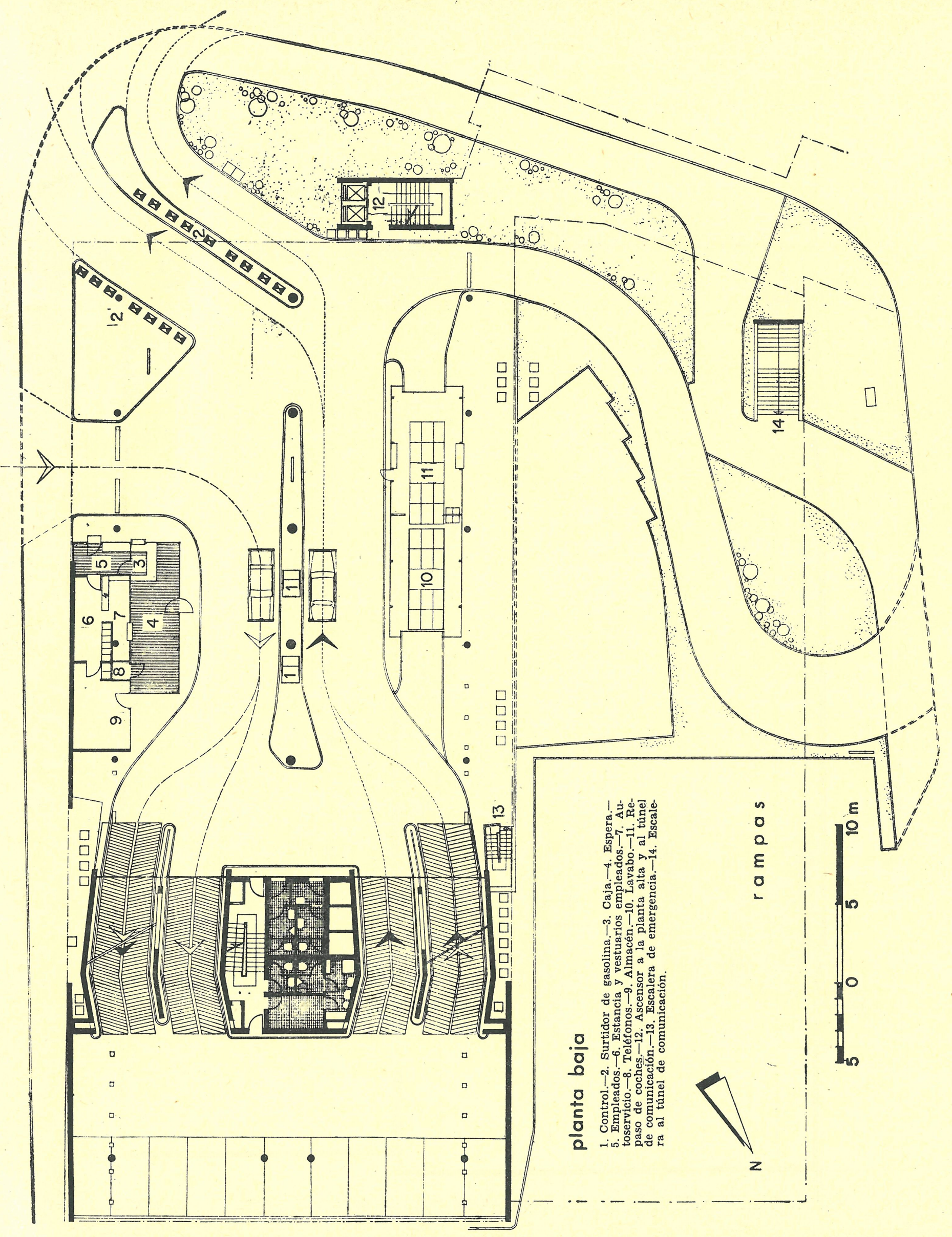




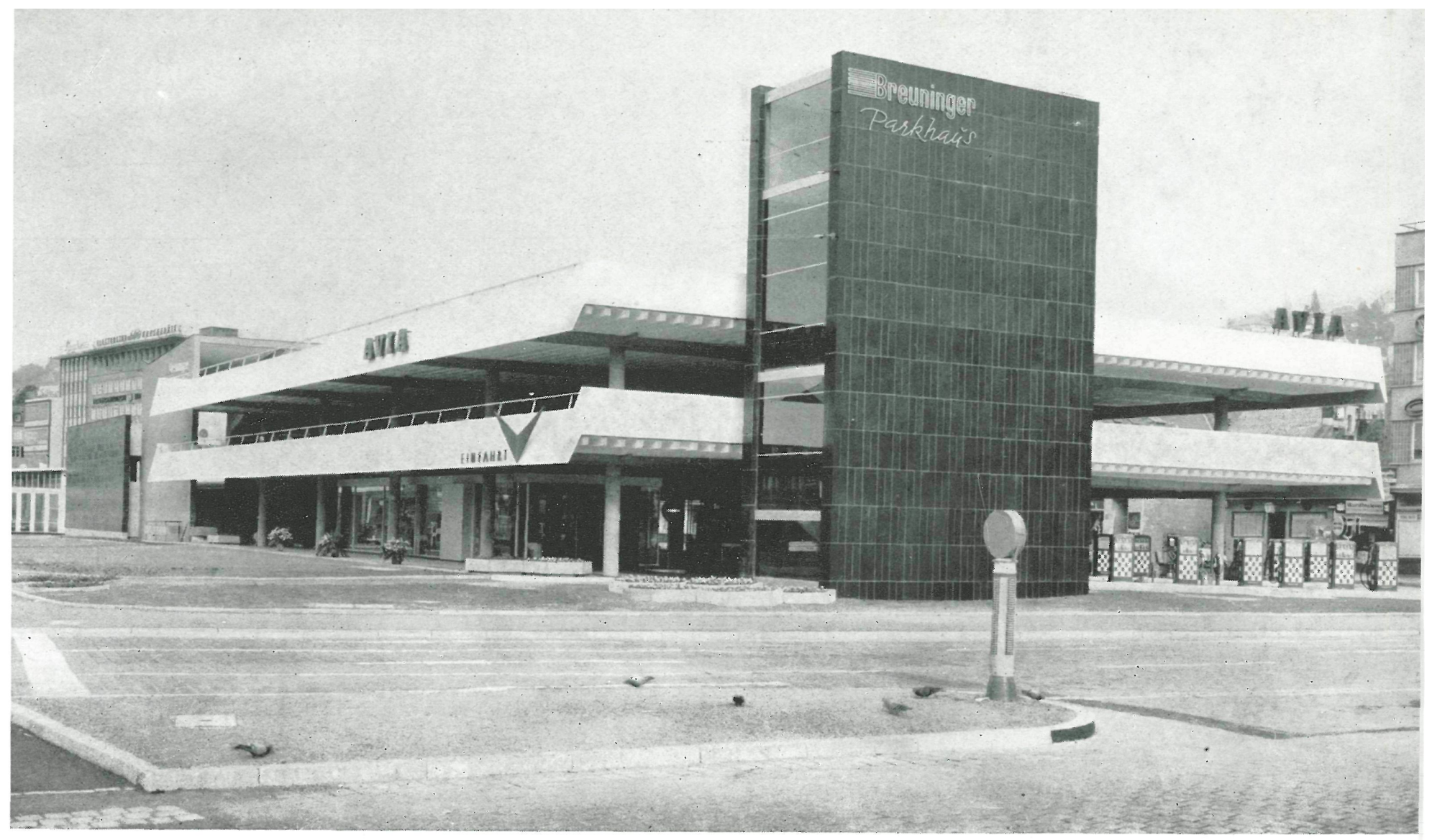

Este aparcamiento comprende un servicio completo, que abarca también andenes de aparatos para combustible, lavado y engrase.

No se ha omitido ningún detalle, hasta el extremo de precaver la posibilidad de incendio, salvando el peligro consiguiente con puertas metálicas e instalación especial y automática de riego de agua por duchas, mecanismo que empieza a funcionar cuando se alcanza la temperatura de $72^{\circ} \mathrm{C}$.

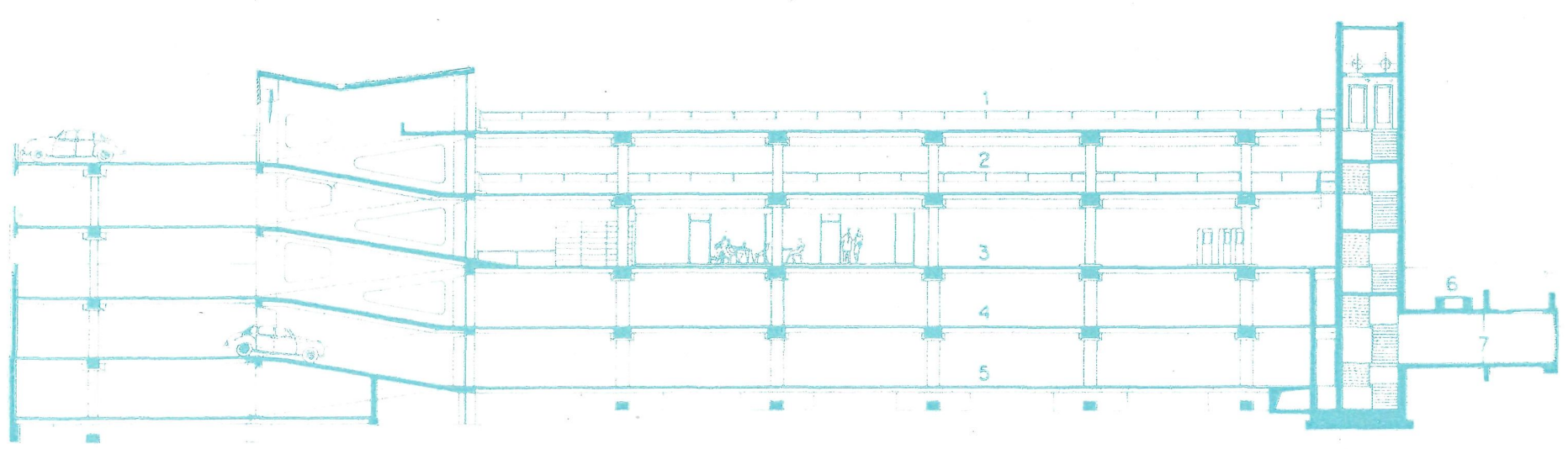

1. Terraza cubierta.-2. Planta primera.-3. Planta baja.-4. Sótano primero.-5. Sótano segundo.-6. Ventilación.-7. Túnel de comunicación. 

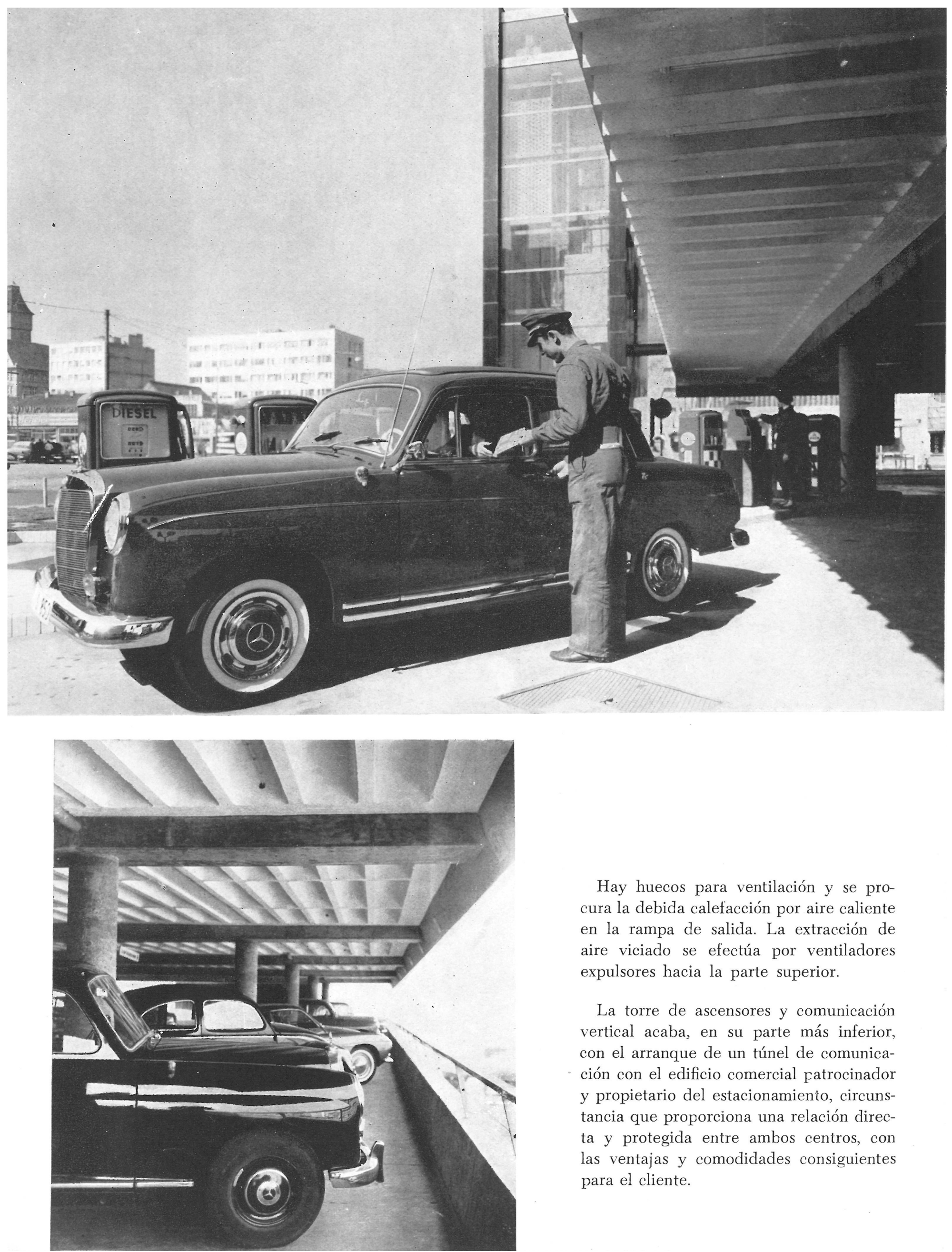

Hay huecos para ventilación y se procura la debida calefacción por aire caliente en la rampa de salida. La extracción de aire viciado se efectúa por ventiladores expulsores hacia la parte superior.

La torre de ascensores y comunicación vertical acaba, en su parte más inferior, con el arranque de un túnel de comunicación con el edificio comercial patrocinador y propietario del estacionamiento, circunstancia que proporciona una relación directa y protegida entre ambos centros, con las ventajas y comodidades consiguientes para el cliente. 
El tratamiento exterior se ha cuidado plásticamente, de forma que su arquitectura y materiales correspondieran al aspecto estético del centro urbano del que forma parte.

La elevación de la torre de ascensores tiende a crear un elemento de contraste con la horizontalidad marcada del edificio, y una armonía urbanística con la verticalidad acusada de la torre de la iglesia Leonhard, situada frente al bloque de la casa Breuninger.

El hormigón de pilares y viguería se deja visto, así como las superficies hormigonadas de algunos paramentos verticales. Las pantallas inclinadas de los alzados están compuestas de elementos prefabricados. Completan el conjunto, chapados de piedra, y zonas acristaladas, constituyendo una unidad sencilla $y$ de indudable belleza, acorde con los edificios circundantes.
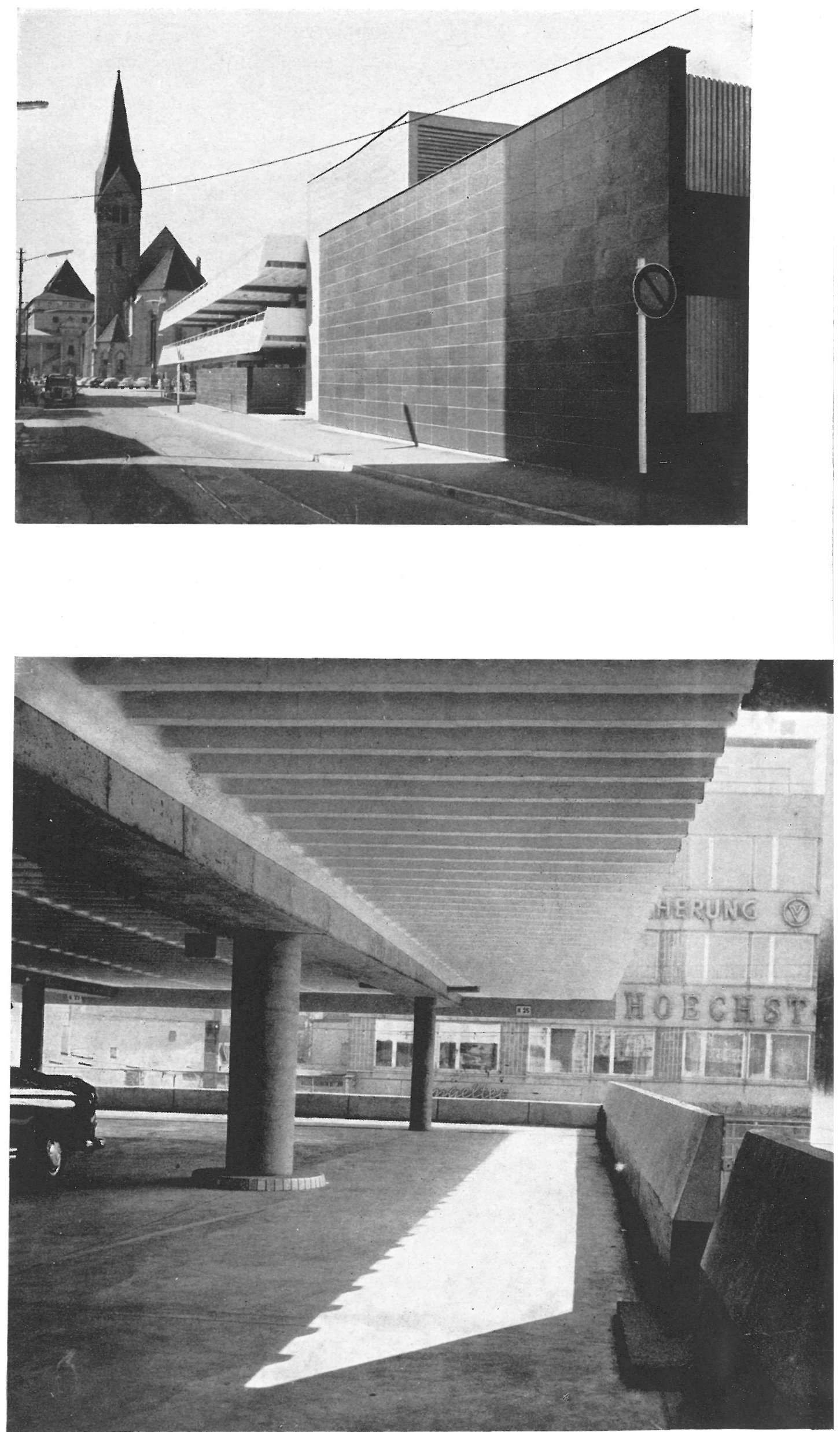


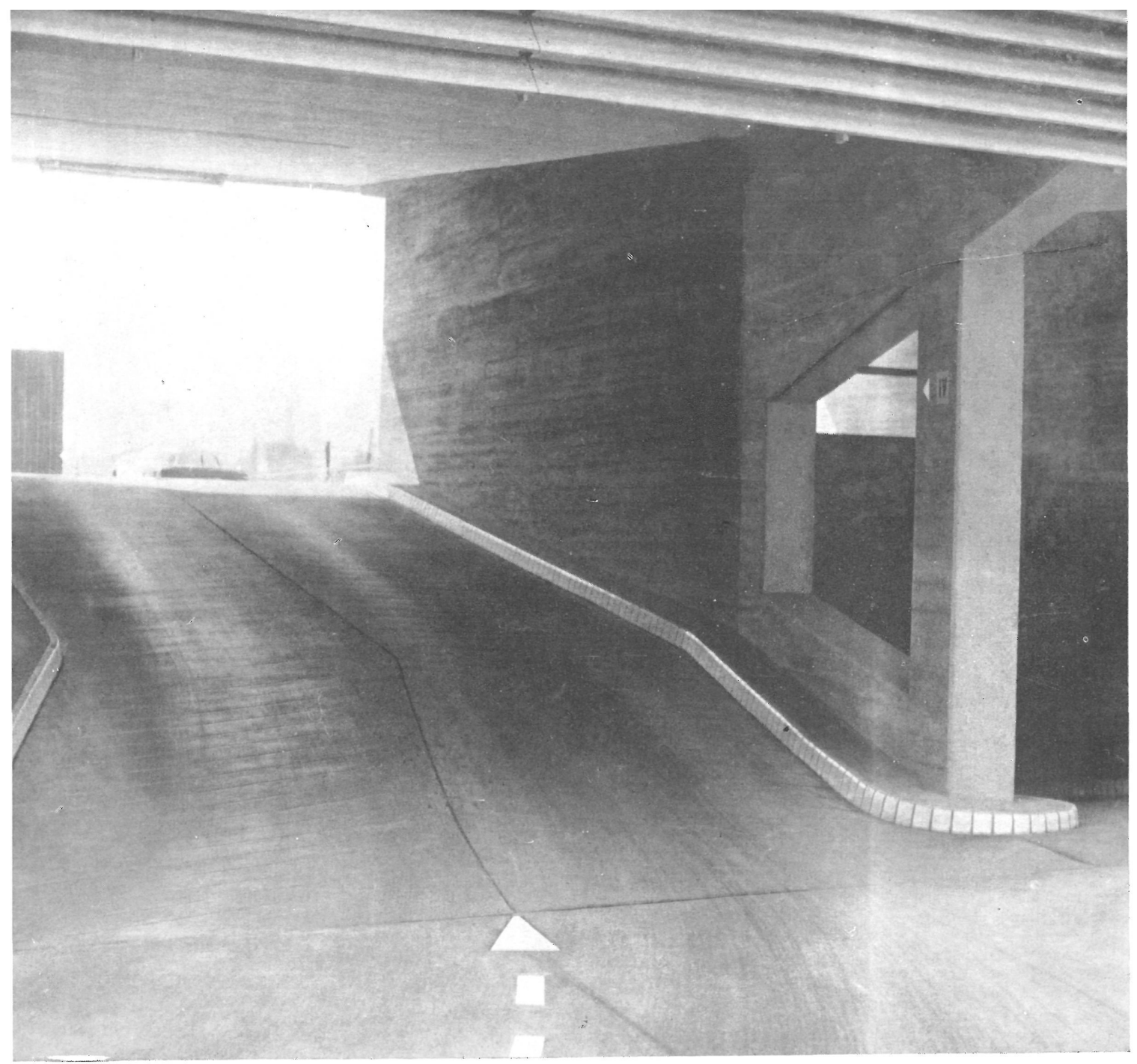

$r a m p a s$

Dada la enorme afluencia de $-$ vehículos, cuyo aumento se preFotos: JÄGER DE STUTTGART vé muy acusado en los próximos años, y puesto que en la calle Leonhard todavía no se ha edificado la totalidad de solares existentes, se organiza la estructura y programación de manera que permita la elevación de una nueva planta cuando sea necesario.

Se han cuidado, asimismo, las inmediaciones del estacionamiento, mediante isletas ajardinadas y grupos de maceias hexagonales que realcen el edificio y proporcionen vistas de color vibrante y alegre.

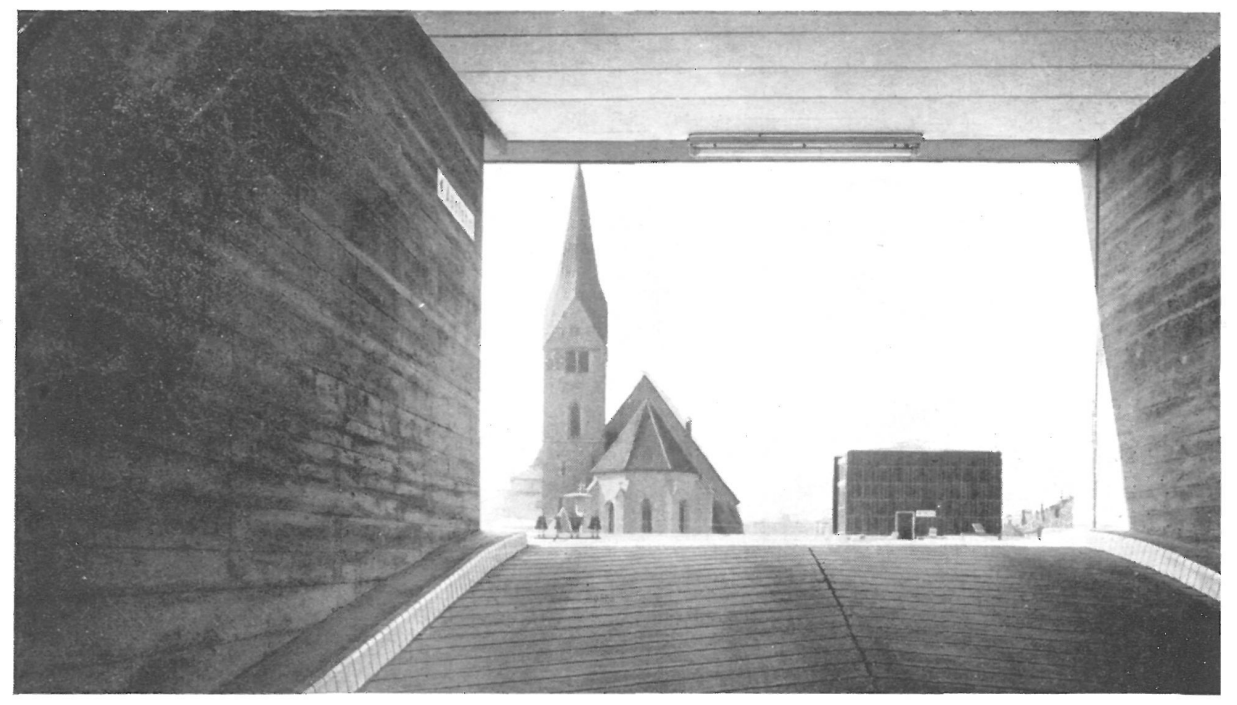

